\title{
Ventricular septal defect and mitral regurgitation secondary to myocardial infarction
}

Sir:

Since I had the opportunity of replying (Fleming, 1973a) to the letter of Bethea et al. (1973) on this subject, the patient I originally reported went into congestive cardiac failure. His extremely good mental and physical condition at the age of 68, nearly 9 years after his myocardial infarction, meant that surgical repair of his defect had to be considered. He was, therefore, fully reinvestigated (Bethea et al., 1973). The ventricular septal defect remained, with a pulmonary blood flow twice the systemic flow. The giant ' $v$ ' waves in the indirect left atrial pressure trace at the time of investigation 9 years previously had disappeared and he now had a ' ' wave of $19 \mathrm{mmHg}$, with an ' $a$ ' wave of $17 \mathrm{mmHg}$. Left ventricular studies showed an end-diastolic pressure of $15 \mathrm{mmHg}$ and the left ventricular cineangiogram confirmed the presence of the ventricular septal defect but showed no more than trivial mitral incompetence. On 6 March 1974 Mr. B. B. Milstein operated through the right ventricle to repair a fenestrated ventricular septal defect near the apex of the heart. It was noted that there was a very large healed inferior infarct. At the time of the infarction the posterior papillary muscles must have been involved.

The patient made an excellent recovery, leaving hospital on the thirteenth postoperative day and remains well.

The ' $v$ ' wave reported earlier (Fleming, 1973b), two months after the myocardial infarction, has disappeared.
It is possible that this was caused by a combination of left ventricular overload and papillary muscle dysfunction. It was evidently not due to organic mitral regurgitation, as originally suggested.

H. A. Fleming, Papworth Hospital, Papworth Everard, Cambridge $\mathrm{CB}_{3}$ 8RE.

\section{References}

Bethea, C. F., Peter, R. H., Behar, V. S., and Kong, Y. (1973). British Heart fournal, 35, 1205.

Fleming, H. A. (1973a). British Heart fournal, 35, 1206.

Fleming, H. A. (1973b). British Heart fournal, 35, 344.

\section{Addendum}

Seven weeks after operation the patient died suddenly.

At necropsy, there was a recent thrombus occluding the right coronary artery near its origin-with recent infarction.

The ventricular septal defect was satisfactorily closed.

The large old inferior infarct was confirmed and this was replaced by fibrous tissue which approximated to the base of the posterior papillary muscle. There was, however, no histological evidence of old scarring in this papillary muscle.

There was also extensive atherosclerosis in vessels elsewhere in the body. 